\title{
Analysis of the Application of Big Data in Intelligent Tourism Mode
}

\author{
Wanchun Zhu ${ }^{1, \text { a }}$ \\ ${ }^{1}$ Guizhou Minzu University, Guiyang 550025 \\ ${ }^{\mathrm{a}}$ email
}

Key words: Intelligent Tourism, Big Data, Intelligence Management, Intelligence Service, Wisdom Marketing

\begin{abstract}
With the sustained growth of China's national economy, tourism has become a "spice" of national life. The annual tourism revenue to a new high more than 4 trillion yuan in 2015 of our national, according to the National Tourism Administration issued the "China Tourism Development Report (2016)" data show. The rising of the data will directly indicate the coming of the era of the whole people's travel, at the same time, with the development of social information technology, the public awareness of the Internet continues to improve, people also put forward higher requirements on the tourism quality, service and innovation. In order to make the tourism industry develop with the times, Jiangsu province took the lead to put forward the new concept of "Intelligent Tourism" in the whole country in 2010. It will make the Internet and other related technology and the development of tourism innovation and development for the ideas be made one, for the tourism industry. Currently supporting the development of intelligent tourism related technologies have been gradually mature, tend to improve. A large number of effective resources provided by the large number of effective resources to become a major force in the development of Intelligent Tourism in this process, mainly reflected in the three aspects of tourism management, tourism services and tourism marketing. This thesis will make a concrete analysis and Research on the application of big data in Intelligent Tourism mode.
\end{abstract}

\section{The Concept of "Wisdom Tourism" and Its Development}

"Intelligent Tourism" is also called "noopsyche tourism", the indispensable factor is the comprehensive application of high-tech information technology such as cloud computing, Internet of things and so on. Tourism operators can use the network for the majority of the audience in a timely manner to release the relevant enterprise dynamic and tourism information, the audience with mobile phones, computers and other network terminal devices active sensing the class information. If the crowd have a travel plan can be reasonable arrangements for the trip, such as booking tickets, hotels, restaurants, etc., to prepare for the trip ahead of schedule. Such an intelligent development model for the convenience of passengers, while have played a huge role in boosting the management of tourism enterprise.

The new concept of "Intelligent tourism" was first put forward and implemented by Jiangsu Province and opened up the perception of Zhenjiang in Zhenjiang, intelligent tourism new space project has become a model for the industry and also opened the curtain for the creation of Intelligent Tourism. A number of technologies involved in various fields has been used to promote, the intelligent tourism development. Subsequently Fujian, Nanjing, Luoyang and other places have also been put into the tide of development of intelligent tourism which has made a deep practice to explore, lay the foundation for further development. Look at the wisdom of tourism development is the form of increasingly diverse, blossom everywhere and innovative. The application of the more common to a number of local scenic 
spots and major portals to establish close cooperation, the establishment of dynamic monitoring and evaluation system of tourist attractions, visitors can understand the dynamic tourism information whenever and wherever possible, and give the evaluation to the area of the service experience which has become a scenic area to improve their own valuable advice, but also an important reference for others to travel. Intelligent tourism development model has been highly valued by the state, the government supports strongly, the relevant provisions of the policy is also issued in succession. The increasing optimization of the policy environment provides the necessary conditions for the rapid development of intelligent tourism, wisdom tourism will usher in the rapid construction of the new era in the future.

\section{Analysis on the Application of Big Data in Intelligent Tourism Mode}

Compared with the traditional tourism, intelligent tourism emphasizes the intelligent, which breaks through the traditional mode of the information release and feedback and pay more attention to the process of tourism before, during and after the relevant information and information related to the acquisition and re integration optimization, so as to bring more convenience to visitors and unique experience which requires big data as a fulcrum, only rely on big data to provide sufficient data support, in order to accurately obtain the intention, flow and satisfaction of tourists. The development of big data has become the trend of the times. Mr. Ma, founder of the Alibaba, said in a speech focused on: "the future of the era will no longer be the IT era, but the DT era, that is, Technology Data data technology which makes nearly $20 \%$ enterprises bigger and stronger, to the other $80 \%$ of the enterprises are still at a loss. But the DT in different times, traditional companies have experienced the baptism of time after IT has been slow to accept the network thinking, big data exactly so that they see a new round of hope, $80 \%$ of the enterprises are ready to fully release. Enough to be seen, big data will play a great role in promoting the development of society in the future. Below there is an analysis on the big data on the intelligent tourism management, services, marketing, the three major aspects of the specific application and boost.

Big data in the intelligent tourism in the application of the most direct manifestation of the change in the direction of management. Buy the tickets on the spot, to the traditional management mode to the car, the tourism enterprises in a very passive situation, because they can not accurately budget tourists, more just by virtue of the experience of previous years roughly estimate, temporary arrangements will inevitably be confused, encountered rain and snow and other inclement weather will once fell into chaos. Big data applications to change the passive situation of traditional tourism regulation, to modern, scientific and technological management. With the help of information technology, enterprises can obtain accurate number of tourists and information for the first time, the use of data analysis system, the vast amount of information classified and integrated into a very valuable information assets of tourism enterprises and based on assets, targeted process management or real-time management, is less effective, and effectively improve the enterprise decision-making ability, insight, realize low cost, high profit and output. At present, many tourism enterprises and local public security, transportation, industry and Commerce and other important departments to form a linkage of information sharing and collaboration, combined with tourism information data can form a strong timeliness of tourism forecasting and early warning management mechanism. Such as the weather, safety, time and other issues can change area in advance for sending information to remind visitors, the tourism supervision department of emergency management ability can be improved, effectively protect the personal safety of tourists and travel experience.

Consumers will be more than three ways to reduce the risk of the goods usually, in the deep level is 
also the need for more information on the enterprise and the big data era of huge amounts of information to better meet this demand and facing a large amount of initialization information may not lead to consumers more intelligent decision-making. However, the use of large data integration and optimization, but it can make the data from more to less, from miscellaneous to fine, so as to affect the final decision of the consumer.

At present, in addition to the official information published by the company, the evaluation of network public opinion has also become an important factor affecting the development of enterprises can not be ignored. Under the era of big data, data sharing mechanism makes others experience increasingly become the precursor ID experience. This will directly subvert the tourism consumption of the "after" feature, more and more people will be the feelings of others as the first reference elements of travel. And the network evaluation system supported by the big data can be captured in time to the most timely and true evaluation of the audience on the social media, such as scenic spots, services, etc. And this kind of evaluation also can fairly and objectively reflect the real face of the scenic spot, directly affect the business situation of the scenic spot. Good evaluation will play a good role in promoting the promotion of the role of tourists to join, and poor evaluation will naturally bring a series of negative impact on the scenic. In the face of the public evaluation of fragmentation, the complexity of tourism, online reputation to build the core should not be blindly outstanding praise, cover the bad, but from the root of the problem, carries on the reorganization and analysis, the integrated use of big data will be the first time, "big data" simplified "tiny information". Tourism enterprises can improve service based on small information, optimize management, in a more scientific and convenient way to promote government management, business operations and consumer decision-making.

For tourists, the main purpose of the trip is to relax the mind and body but the traditional mode of travel will inevitably appear cursory, crowd phenomenon, not only physical and mental pleasure, but also tired, makes a lot of people go away. The intelligent tourism to help tourists to get rid of the bad experience, nip in the bud opening service mode and visitors through the network to get information in advance of the attractions, a reasonable plan to travel plans, anytime, anywhere online booking products, feel the new service experience of information technology. For the intelligent tourism services more targeted, large data analysis has become a very important part. Usually tourism enterprises will be tourists to eat, live, travel, travel, shopping, entertainment, based on the elements of the six activities, respectively, to establish a horizontal and vertical dimensions of the expansion analysis model which will be distributed to a large amount of data systematically presented in a list, to facilitate visitors to arrange the trip, to promote the purchase behavior. Such as the development of Ctrip is effective in the application of large data, independent research and development of Ebooking, Obooking, Vbooking and other data systems, The advantages of the online platform and the ground service system for organic integration and seamless. Consumers can be scheduled through the network platform tickets, hotels, tickets, etc., while also innovative development of hotel reservation mode. A hotel can store data, to sell to other hotels, consumers in the hotel under the condition of unknown name, location, price and evaluation of multi angle selection according to the hotel, the hotel name after obtaining success, and can enjoy low discount, this model seems vague, it is fast, affordable to avoid vicious competition.

\section{For Visitors to Bring Personal Experience}

The development of agriculture and industry in our country has met people's material needs. In the premise of the material needs to be met, the public's demand for the spirit is also more and more strong, this is the original intention to experience the economy. In this new economic form, the consumer is not 
satisfied with the products to meet the functional, more eager to get different experience from the product, so the travel personality design, emotional sustenance, environmental protection concept will be put on the agenda. According to a travel agency survey data, the number of visitors to the domestic folk customs of the scenic area is higher than that of the natural scenery and places of historic interest and scenic beauty the number of scenic spots, tourist groups many single form development to vacation travel, travel, travel direction of the individual characteristics. Therefore, human personalized consumer demand increasingly strong, the future potential of the market scale and the consumption custom should not be underestimated.

The development of intelligent Tourism is to give full attention to the personality of the consumer experience, with big data analysis, to understand the inherent needs of consumers. To "private custom" as the idea, start planning and management. For example, some places will be specially designed for tourists fishing, fruit and vegetable picking links and many eager consumers. Rather than say that such a consumer behavior is the purchase of product features, it is better to buy a new experience. In the traditional tourism demand structure, the tourists generally pay attention to the quality of the attractions and how much, but in today, the proportion of tourists to the emotional experience significantly increased. Now, like "where Daddy"'ultimate challenge" and so on all kinds of television reality show also has provided the enormous enlightenment function for the wisdom travel personalized experience. Column group will be set up according to the characteristics of the scenic area of the game links, so that visitors involved, in the entertainment experience of the unique folk customs.

The application of big data is a typical application in the marketing strategy, in the traditional tourism industry often wantonly through advertising and engage in activities to achieve the purpose of marketing, with the method of cost, difficult to guarantee the effect of malpractice. Big data era, the wisdom of travel can easily integrate $\mathrm{O} 2 \mathrm{O}$ marketing model through the line will be discounted, concessions and other attractive information to Internet users, driven by the dual consumer behavior online and offline. In addition Intelligent Tourism through tourism public opinion monitoring and data analysis, you can quickly tap the tourist hot spots and tourist interest points. As a starting point, and constantly guide the tourism enterprises planning the corresponding tourism products, develop the corresponding marketing theme, so as to vigorously promote the tourism industry's products and marketing innovation. In addition, the use of new media marketing wisdom can be micro-blog, WeChat and other easy forwarding and sharing features and other advantages, by means of fan popularity, the power circle of friends and other related data accumulation of tourists, gradually formed from the media marketing platform, to achieve precision marketing.

\section{Conclusion}

Throughout the development and construction of the wisdom of tourism, a lot of time due to the lack of understanding of the leader or excessive reliance on big data, there is a big data can decide everything. It leads to a lot of blind decision-making, so that a large number of technical inputs did not play the desired effect. The awareness of big data, also should be clear about the future development trend of the era of big data, valuable in-depth analysis of large data, focusing on the human subjective initiative, examine the long-term game between human and future data from all forms of the means and characteristics of centralized privacy. 


\section{Reference}

[1] Zhongliang Shen. Big data is equal to the intelligent tourism? Current situation and future of China Travel News.2014-12-04.

[2] Xiaorui. Big data help to open the intelligent tourism mode. Big data observation.2016-05-23.

[3] The Intelligent Tourism: the era of big data has arrived. Tourism NetEase. 2014-11-21.

[4] Kai Weng. Big data in the intelligent Tourism Research on the application of [J]. technology innovation and application of, 2015 (24): 87-88.

[5] Chengkui Luo. Big data technology in the application of [J]. intelligent tourism overview monthly, 2013 (8). 